\title{
Comparative Rooting of Shoot Tips of Four Japanese Persimmon Cultivars vs. Shoots Regenerated from Roots Cultured In Vitro
}

\author{
Takuya Tetsumura ${ }^{1}$ and Hisajiro Yukinaga ${ }^{2}$ \\ Experimental Farm, Graduate School of Agriculture, Kyoto University, \\ Takatsuki, Osaka 569-0096, Japan
}

Additional index words. Diospyros kaki, organogenetic capacity, pericycle, precocity, rejuvenation, subculture, variant, zeatin

\begin{abstract}
When cultured in vitro, roots of four Japanese persimmon (Diospyros kaki L.) cultivars formed adventitious shoots on MS medium with $10 \mu_{\mathrm{M}}$ zeatin and $0.01 \mu \mathrm{M}$ indole3 -acetic acid, although their organogenetic capacities varied. Histological study revealed that the origin of the adventitious shoots was the pericycle. The regenerated shoots grew well on the shoot proliferation medium (MS with $5 \mu$ zeatin). Final rooting percentages of shoots regenerated from roots of three of the four cultivars were greater than those of shoots that originated from shoot tips and that had been subcultured $>50$ times. Shoots regenerated from 'Jiro' roots rooted 10 days earlier, had more roots than those from shoot tips, and maintained higher rooting ability over ten subcultures. Rooted 'Hiratanenashi' shoots regenerated from roots survived better after acclimatization than those from shoot tips. No obvious variants were observed either in vitro or in the field. The trees regenerated from roots flowered within 4 years. These findings suggest that partial rather than true rejuvenation was responsible for both the early flowering and the juvenile characteristics, i.e., the enhanced rooting ability, observed in the regenerated plants. Chemical name used: 6-(4-hydroxy-3-methylbut-2-enylamino) purine (zeatin).
\end{abstract}

In several tree species, rooting remains one of the most critical steps of micropropagation. Although successful methods for micropropagating Japanese persimmon have been previously developed (Tao and Sugiura, 1992a), their application in commercial production has been limited because microcuttings are generally difficult to root (Tetsumura et al., 1991). In addition, more than half of the cultivars tested by Fukui et al. (1992) have low rooting ability. Long-term subculture with benzyladenine (BA) has improved the rooting ability in some cultivars that rooted poorly when subcultured with zeatin, but 74-76 subcultures (6.5 years) were required before satisfactory rooting percentages could be obtained (Tetsumura, 1997).

Received for publication 1 May 1999. Accepted for publication 2 Nov. 1999. This work was partially supported by Grant-in-Aid no. 06760030 for Encouragement of Young Scientists to TT from the Ministry of Education, Science, Sports and Culture, Japan. We thank R. Tao for helpful suggestions and review of this manuscript, $\mathrm{M}$. Mineyama and $\mathrm{H}$. Wakahara for maintenance of the trees, and S.K. Kang for technical advice on microscopy. The cost of publishing this paper was defrayed in part by the payment of page charges. Under postal regulation, this paper therefore must be hereby marked advertisement solely to indicate this fact.

${ }^{1}$ To whom reprint requests should be addressed. E-mail address: tetsumur@ farm.kyoto-u.ac.jp

${ }^{2}$ Current address: Dept. of Biotechnology Science, School of Biologically Oriented Science and Technology, Kinki Univ., Wakayama 649-6433, Japan.
In several apple cultivars, adventitious shoots regenerated from root cuttings readily formed their own roots (Robinson and Schwabe, 1977). Furukawa et al. (1990) reported that shoots regenerated from root cultures of Eustoma grandiflorum (Griseb.) Schinners rooted easily and that culture of roots seemed to be useful for micropropagation. Similarly, we believe that if adventitious microshoots regenerated from roots of Japanese persimmon cultivars have higher rooting ability, they will be a better source of stock shoots for micropropagation than the original shoots. To our knowledge, however, the rooting and growth of shoots regenerated from in vitro culture of roots of woody plants has not been investigated. The shoots that arise on root cuttings, when used as softwood cuttings, tend to root more readily than cuttings taken from other parts of the tree (Del Tredici, 1995).

In our previous study (Tetsumura and Yukinaga, 1996), we confirmed highfrequency adventitious shoot regeneration from roots of 'Jiro' Japanese persimmon cultured in vitro. The objective of the present study was to explore the organogenetic capacity of the roots of four Japanese persimmon cultivars and to compare the rooting potential and growth of shoots regenerated from them with those originating from shoot tips. Furthermore, we examined their histology during morphogenesis, and planted trees regenerated from roots in an orchard in order to investigate their precocity and possible variation.
Original plant materials. Micropropagated plantlets of four cultivars derived from in vitro shoot cultures of Japanese persimmon were used as source material. The rooting ability of 'Jiro' is high, that of 'Hiratanenashi' moderate, and that of 'Hana Gosho' and 'Fuyu' low. Shoot cultures from dormant buds were established as described by Tao and Sugiura (1992a). Shoot multiplication cultures were maintained for more than 4 years by subculturing at 30-d intervals (>50 subcultures) on Murashige and Skoog (MS) salts plus vitamins (Murashige and Skoog, 1962) with $5 \mu \mathrm{m}$ zeatin (multiplication medium). Rooting was induced by dipping the basal ends of shoots $\approx 1 \mathrm{~cm}$ long in $1.25 \mathrm{~mm}$ indole-3-butyric acid (IBA) in 50\% ethanol for $10 \mathrm{~s}$, after which the shoots were placed on half-strength MS with half the normal strength of nitrates and without growth regulators (rooting medium). After $40 \mathrm{~d}$ in the rooting medium, lateral roots were removed from the primary roots originating from the shoots. These primary roots were excised from the shoots, measured, and used for the regeneration experiment.

Regeneration from roots. Root segments were cultured on MS medium supplemented with $10 \mu_{\mathrm{M}}$ zeatin and $0.01 \mu_{\mathrm{M}}$ indole3 -acetic acid (regeneration medium) to induce adventitious shoots (Tetsumura and Yukinaga, 1996). The percentage of root segments forming adventitious shoots was determined after $60 \mathrm{~d}$ of culture, the number that formed more than five was also recorded. There were 10 to 32 root segments per cultivar, and the experiment was conducted four times.

Histology. After 0-30 d on the regeneration medium, small pieces $(5-10 \mathrm{~mm})$ of the 'Jiro' roots were fixed in a solution of $2.5 \%$ glutaraldeyde in $0.1 \mathrm{~m}$ cacodylate buffer $(\mathrm{pH}$ 7.2). Tissues were dehydrated in a graded ethanol series, and then infiltrated with acrytron E (Mitsubishi Rayon Co., Tokyo). Sections $\left(4 \mu_{\mathrm{M}}\right)$ were cut with a glass knife, stained in $0.05 \%$ toluidene blue $\mathrm{O}$, and observed by light microscopy.

Rooting and growth. Adventitious shoots were excised from the roots, adjusted to apical buds containing two leaves, and cultured once on multiplication medium. The number of shoots, the height of the tallest shoot, and the number of leaves were recorded after $30 \mathrm{~d}$ of culture. The rooting treatment, as stated above, was then carried out with shoots $\approx 1 \mathrm{~cm}$ long. The percentage of shoots forming adventitious roots was examined at 10-d intervals, and the number of adventitious roots per rooted shoot was determined at the end of the culture period. Ten shoots were used per cultivar, and the experiment was conducted four times. The experiments were also conducted on mother stock shoots that originated from shoot tips and produced adventitious roots that were used for regeneration experiments.

The rooted shoots were potted and acclimatized according to Tetsumura et al. (1993). After the rooting medium was rinsed off in 
sterile water, rooted shoots were planted in 60 $\times 60$-mm pots filled with fine vermiculite, and the medium was saturated with half-strength liquid MS salts with half the normal strength of nitrates and without sucrose, in $75 \times 100$ $\mathrm{mm}$ polycarbonate vessels that were autoclaved. Between 30 and $60 \mathrm{~d}$ after planting, the cover was gradually removed from the vessel. Survival percentage, plant height, the number of new leaves that developed after potting, and the dry weight of the top were recorded $30 \mathrm{~d}$ after acclimatization. Since the acclimatization experiment was carried out after the rooting experiment, the number of plants ranged from 2 to 10 depending on the percentages of rooting. The experiment was conducted four times.

Changes in rooting ability during subculture. Shoots regenerated from 'Jiro' roots were subcultured 10 times on multiplication medium, and changes in their rooting ability during subcultures were evaluated. At each subculture, 20 shoots were used for the rooting test, and the rest were planted on multiplication medium. The experiment was conducted twice, and the mother shoots were also used for the same rooting test. Rooting was recorded after $20 \mathrm{~d}$ of rooting treatment.

Throughout the course of the experiments, all of the media contained $0.8 \%(\mathrm{w} / \mathrm{v})$ agar (Wako Pure Chemicals Co., Tokyo) and 0.09 M sucrose. The $\mathrm{pH}$ of the media was adjusted to 5.7 before autoclaving at $121{ }^{\circ} \mathrm{C}$ and 120 $\mathrm{kPa}$ for $15 \mathrm{~min}$. Two root segments or three to four shoots were placed in an Erlenmeyer flask $(100 \mathrm{~mL})$ containing $30 \mathrm{~mL}$ medium. However, the volume of the rooting medium was $50 \mathrm{~mL}$. Cultures were maintained at $28^{\circ} \mathrm{C}$ under a 16-h photoperiod, except for dark incubation for the initial $10 \mathrm{~d}$ of the rooting treatment (Murayama et al., 1989) and continuous lighting for acclimatization (Tetsumura et al., 1993), with a photon flux of $60 \mu \mathrm{mol} \cdot \mathrm{m}^{-2} \cdot \mathrm{s}^{-1}$ provided by cool-white fluorescent lamps.

Field performance. After acclimatization, the plantlets regenerated from roots and those that originated from shoot tips of both 'Jiro' and 'Hiratanenashi' were transplanted to $20 \times$ 20-cm clay pots, grown outdoors for a year, and then established in clay loam in an orchard of the Experimental Farm of Kyoto Univ. One-year-old nursery trees grafted on seedlings were also established. Nine trees per treatment per cultivar were planted in a randomized block design with three blocks. Flowering was recorded in May. In addition to these trees, 30 trees regenerated from 'Jiro' roots were planted in the same orchard to determine if there was variation in the regenerants from roots.

Statistical analysis. All data were subjected to analysis of variance (ANOVA) and cultivar means were separated by Duncan's multiple range test. Percentage of data were subjected to arcsin transformation before analysis.

\section{Results}

Regeneration from roots. Root segments of the four cultivars tested produced adventitious shoots (Table 1). Shoot regeneration was more prolific from 'Jiro' roots than from the other cultivars, because about one-half of the root segments produced more than five adventitious shoots. Comparison of regeneration capacity of roots among cultivars was confounded by the greater tendency of longer root segments to form adventitious shoots (Tetsumura and Yukinaga, 1996), and the mean length of the root segments varied with cultivar. However, the roots of 'Hana Gosho' demonstrated the lowest regeneration capacity of all of the cultivars tested, since its percentage of adventitious shoot formation was the lowest, although its mean root length was the longest.

Histology. Adventitious roots, which were tetra- or pentarch, consisted of a single epidermal layer, a parenchymatous cortex containing starch grains, a single-layered endodermis and pericycle, and a central vascular cylinder without pith (Fig. 1A). On regeneration medium, the roots began to show secondary thickening; then the meristematic tissue appeared in a proliferated pericycle below the protoxylem poles between the phloem bundles (Fig. 1B), expanded centrifugally, and became an adventitious shoot primordium (ASP) (Fig. 1C). When the ASP was about to emerge, a procambial strand elongated to the ASP from the vascular cambium of the root (Fig. 1D). Finally, the ASP differentiated into a shoot bud with a distinct shoot apex and leaf primordium, and emerged from the root (Fig. 1E).

Rooting and growth. Shoots regenerated from roots seemed to grow more vigorously than those that originated from shoot tips after $30 \mathrm{~d}$ on multiplication medium, and there were significant differences in the number of leaves of 'Jiro' and the number of shoots of 'Hana Gosho' (Table 2). However, there were no significant differences in the height of the tallest shoots within cultivars. No variants were observed among the shoots regenerated from roots of the four cultivars.

Shoots regenerated from roots rooted better than those that originated from shoot tips and had been subcultured $>50$ times (Fig. 2). For the low-rooting-ability cultivars, Fuyu and Hana Gosho, the differences in rooting percentages between the two types of shoots were significant after 20 or $30 \mathrm{~d}$ of rooting treatment, and the rooting percentages of shoots regenerated from roots were twice as great as those of shoots that originated from shoot tips after $40 \mathrm{~d}$. Even for the moderate-rootingability cultivar, 'Hiratanenashi', the rooting percentage of shoots regenerated from roots was significantly greater than that of the mother shoots after $40 \mathrm{~d}$. Because of the high rooting ability of the mother shoots of 'Jiro', differences in rooting percentage were nonsignificant at $40 \mathrm{~d}$. However, shoots regenerated from roots rooted $10 \mathrm{~d}$ earlier than those that originated from shoot tips. No differences in the number of adventitious roots per rooted shoot were significant except for 'Jiro', in which shoots from shoot tips formed 2.1 adventitious roots, while those from roots formed 4.7 roots $(P \leq 0.05)$.

After potting, the rooted shoots from 'Jiro' roots grew better than those that originated from shoot tips (Table 3). Although persimmon shoots tend to stop growing during rooting, $53 \%$ of the shoots regenerated from 'Jiro' roots started to grow vs. only $28 \%$ of those that originated from shoot tips. Rooted shoots regenerated from 'Hiratanenashi' roots acclimated more easily than those that originated from shoot tips. As a result, two-thirds of the regenerated shoots subjected to the rooting
Table 1. Length of primary roots induced on in vitro shoots $40 \mathrm{~d}$ after 1.25 mM IBA treatment and subsequent adventitious shoot formation from root segments of four Japanese persimmon cultivars.

\begin{tabular}{|c|c|c|c|}
\hline \multirow[b]{2}{*}{ Cultivar } & \multirow{2}{*}{$\begin{array}{l}\text { Length } \\
\text { of root } \\
\text { segment } \\
\text { (cm) }\end{array}$} & \multicolumn{2}{|c|}{$\begin{array}{c}\text { Root segments } \\
\text { forming adventitious } \\
\text { shoots }(\%) \\
\end{array}$} \\
\hline & & Total & $>5$ \\
\hline Fuyu & $4.5 \mathrm{ab}^{\mathrm{z}}$ & $51 \mathrm{~b}$ & $12 \mathrm{a}$ \\
\hline Hana Gosho & $6.0 \mathrm{c}$ & $31 \mathrm{a}$ & $2 \mathrm{a}$ \\
\hline Hiratanenashi & $3.5 \mathrm{a}$ & $55 \mathrm{~b}$ & $5 \mathrm{a}$ \\
\hline Jiro & $4.4 \mathrm{~b}$ & $85 \mathrm{c}$ & $45 \mathrm{~b}$ \\
\hline
\end{tabular}

Mean separation within columns by Duncan's multiple range test $(P \leq 0.05)$. Values are means of four replications consisting of 10-32 roots each.
Table 2. Comparison of the growth of shoots regenerated from roots (R) with those originating from shoot tips (S) of four Japanese persimmon cultivars after $30 \mathrm{~d}$ on multiplication medium.

\begin{tabular}{lccc}
\hline Cultivar & Origin & No. of shoots & No. of leaves \\
\hline Fuyu & $\mathrm{R}$ & 2.2 & 5.8 \\
& $\mathrm{~S}$ & 2.0 & 5.8 \\
\multirow{3}{*}{ Hana Gosho } & & NS & NS \\
& $\mathrm{R}$ & 2.8 & 6.9 \\
Hiratanenashi & $\mathrm{S}$ & 2.2 & 7.0 \\
& & $*$ & NS \\
& $\mathrm{R}$ & 2.9 & 4.6 \\
Jiro & $\mathrm{S}$ & 3.1 & 4.3 \\
& & $\mathrm{NS}$ & NS \\
& $\mathrm{R}$ & 2.8 & 6.2 \\
& $\mathrm{~S}$ & 2.8 & 5.0 \\
& & $\mathrm{NS}$ & $*$ \\
\hline
\end{tabular}

$\overline{\text { ss, * Nonsignificant or significant difference between origins within cultivars }}$ at $P \leq 0.05$ by ANOVA. Values are means of four replications consisting of 10 shoots each. 


\section{Propagation \& Tissue Culture}

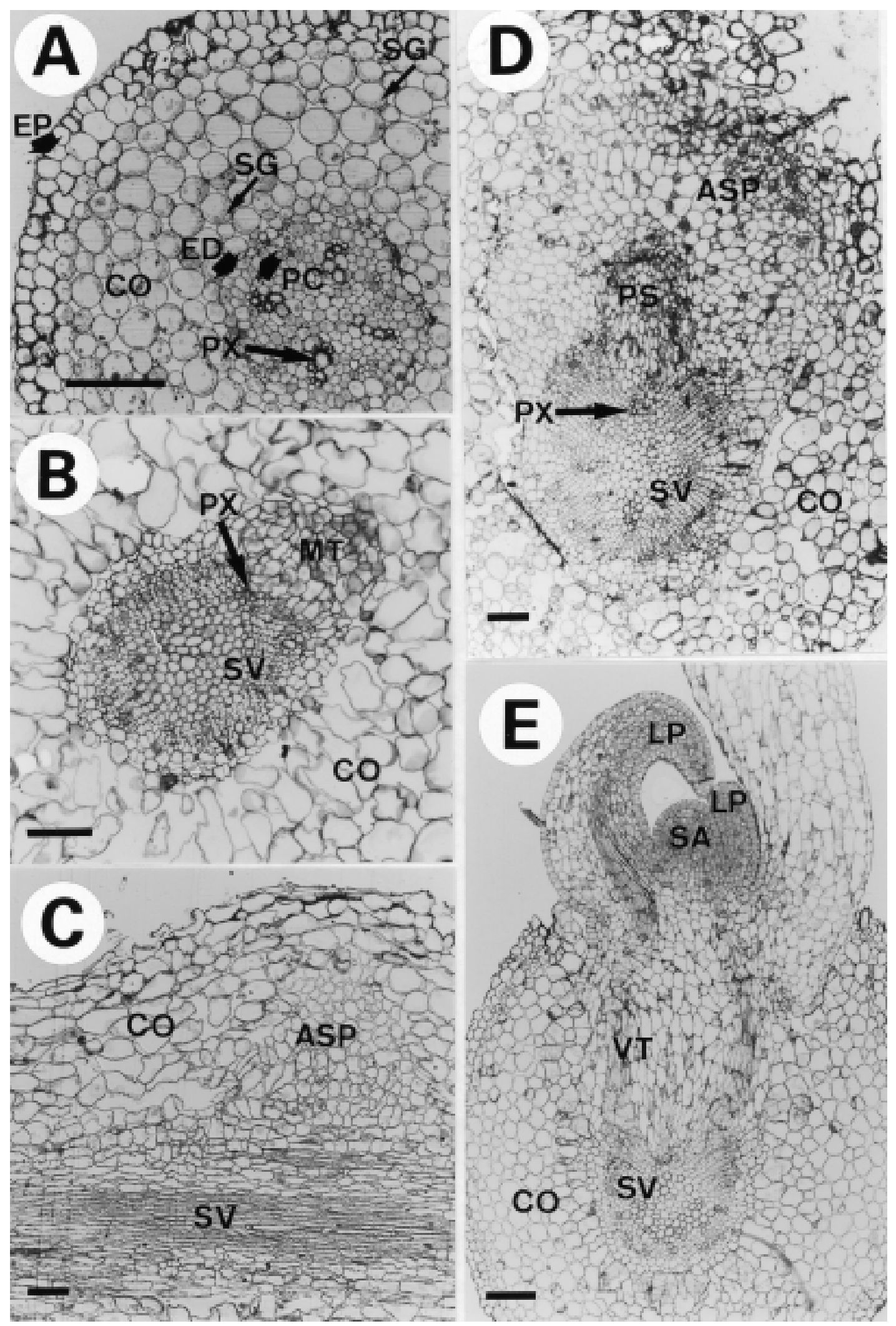

Fig. 1. (A, B, D, and $\mathbf{E}$ ) Transverse and (C) longitudinal sections of 'Jiro' Japanese persimmon roots cultured in vitro. (A) An adventitious root before culture on regeneration medium. Most of the cortical cells contain starch grains. (B) Early stage of secondary thickening after $15 \mathrm{~d}$ on regeneration medium. Meristematic tissue appears in the proliferated pericycle. (C) A protuberance on the root after $18 \mathrm{~d}$ on regeneration medium. An adventitious shoot primordium (ASP) is expanding centrifugally. The endodermis has degenerated. (D) The ASP with a procambial strand after $20 \mathrm{~d}$ on regeneration medium. The cortex and epidermis near the ASP have degenerated. (E) A well-developed shoot bud with a few leaf primodia enclosing a shoot apex. A normal vascular system has been completed from the shoot bud to the main root vascular cylinder. Abbreviations: cortex (CO), endodermis (ED), epidermis (EP), leaf primordium (LP), meristematic tissue (MT), pericycle (PC), procambial strand (PS), protoxylem (PX), shoot apex (SA), starch grain (SG), secondary vascular tissue (SV), vascular tissue (VT). All scale bars $=0.1 \mathrm{~mm}$. 
Table 3. Comparison of survival and growth of plantlets regenerated from roots (R) or shoot tips (S) of four Japanese persimmon cultivars $30 \mathrm{~d}$ after acclimatization.

\begin{tabular}{|c|c|c|c|c|c|c|}
\hline \multirow[b]{2}{*}{ Cultivar } & \multirow[b]{2}{*}{ Origin } & \multicolumn{2}{|c|}{ Survival (\%) } & \multicolumn{3}{|c|}{ Growth of surviving plantlets } \\
\hline & & $\begin{array}{c}\text { Per shoot with } \\
\text { rooting treatment }\end{array}$ & $\begin{array}{c}\text { Per rooted } \\
\text { shoot }\end{array}$ & $\begin{array}{l}\text { Plant ht } \\
(\mathrm{cm})\end{array}$ & $\begin{array}{l}\text { Leaves } \\
\text { (no.) }\end{array}$ & $\begin{array}{l}\text { Top dry } \\
\text { wt }(g)\end{array}$ \\
\hline \multirow[t]{3}{*}{$\overline{\text { Fuyu }}$} & $\mathrm{R}$ & 48 & 78 & 27.7 & 11.4 & 3.6 \\
\hline & $\mathrm{S}$ & 23 & 83 & 28.2 & 11.4 & 2.9 \\
\hline & & $*$ & NS & NS & NS & NS \\
\hline \multirow[t]{3}{*}{ Hana Gosho } & $\mathrm{R}$ & 60 & 90 & 24.5 & 13.5 & 3.2 \\
\hline & $S$ & 30 & 96 & 24.2 & 12.9 & 3.7 \\
\hline & & $*$ & NS & NS & NS & NS \\
\hline \multirow[t]{3}{*}{ Hiratanenashi } & $\mathrm{R}$ & 63 & 92 & 26.6 & 14.0 & 3.3 \\
\hline & $\mathrm{S}$ & 33 & 62 & 26.0 & 13.3 & 2.4 \\
\hline & & $*$ & $*$ & NS & NS & $*$ \\
\hline \multirow[t]{3}{*}{ Jiro } & $\mathrm{R}$ & 90 & 98 & 31.0 & 15.1 & 3.1 \\
\hline & $\mathrm{S}$ & 78 & 96 & 25.2 & 12.3 & 1.8 \\
\hline & & NS & NS & $*$ & $*$ & $*$ \\
\hline
\end{tabular}

Ns, * Nonsignificant or significant difference between origins within cultivars at $P \leq 0.05$ by ANOVA. Values are means of four replications consisting of 2-10 plantlets each.

treatment survived after potting vs. only onethird of those from shoot tips. After the rooting treatment, survival in the pots was twice as great for shoots regenerated from roots of the cultivars with low rooting ability than for those that originated from shoot tips. However, no differences were observed in the survival percentages of the rooted shoots and growth after potting.

Changes in rooting ability during subculture. Although there was neither a linear nor a quadratic relationship between rooting percentage of shoots regenerated from roots and the number of subcultures, the mean rooting percentage over ten subcultures was significantly $(P \leq 0.01)$ greater than that of the shoots that originated from shoot tips $(85 \%$ vs. $32 \%)$.

Field performance. Regardless of tree type, $50 \%$ to $66 \%$ of 'Jiro' trees flowered in the first year of establishment, and all flowered in the third year. None of the 'Hiratanenashi' trees flowered in the first year, but $33 \%$ of those micropropagated from shoot tips flowered in the second year and all flowered in the fourth year. The bark, leaves, flowers, and fruits of the two types of micropropagated trees were true-to-type, and no variants were observed among the 30 trees regenerated from 'Jiro' roots.

\section{Discussion}

As previously reported for Prunus hybrid incisa $\mathrm{X}$ serrula (Druart, 1980) and apple rootstock (Malus prunifolia Borkh.) (Masuda et al., 1994), roots of four Japanese persimmon cultivars formed adventitious shoots in vitro without difficulty. Because of the high organogenetic capacity, many regenerated shoots could be obtained from roots even of 'Fuyu', which is considered to be a difficult-to-root cultivar. Regarding 'Hana Gosho', however, the shoots were difficult-to-root and the roots had a lower regeneration capacity, so that we had to prepare more mother shoots to obtain enough roots to investigate the characteristics of the shoots that regenerated from them. Shoots regenerated from roots over 10 subcultures maintained their ability to root. There- fore, once adventitious shoots have formed on roots, a great number of shoots with higher rooting ability can be obtained after multiplying them on the proliferation medium, even for more recalcitrant cultivars such as 'Hana Gosho'.

For Japanese persimmon, adventitious shoots seem to form more easily on roots than on callus derived from primordial leaves. Although Tao and Sugiura (1992b) reported that the callus of 'Fuyu', 'Hana Gosho', and 'Hiratanenashi' did not form any adventitious buds, the root segments of these cultivars did so. Such a high organogenetic potential of roots may be related to juvenility, for as Tamura et al. (1992) have suggested, rejuvenated Japanese persimmon callus has a high capacity for adventitious bud formation, while Bonga (1982) has reported that the roots often retain their juvenility.

Shoots regenerated from roots, which are thought to be in a juvenile phase, as stated above, had a higher rooting ability than their mother shoots in this study. Incidentally, the phenomenon of increasing rooting ability of shoots from adult plants with successive subcultures may be explained by the progressive rejuvenation of these shoots (Sriskandarajah et al., 1982). The number of subcultures required for rejuvenation varies with species and cultivar (Banno et al., 1989; Zimmerman and Fordham, 1985), and is large in some fruit trees: 31 in the 'Red Delicious' apple (Sriskandarajah et al., 1982) and 38 in the 'Jiro' Japanese persimmon (Tao et al., 1994). In this study, the shoots from shoot tip cultures were thought to be rejuvenated to some extent because they were subcultured $>50$ times. However, through adventitious shoot formation on roots, which might have caused greater rejuvenation, we obtained the shoots with higher rooting ability than these rejuvenated shoots.

After potting, the rooted shoots regenerated from roots survived and grew as well as or even better than those that originated from shoot tips. The earlier rooting of the regenerated shoots of 'Jiro' apparently led to a quicker recovery from damage by the rooting treatment. As a result, they developed more new

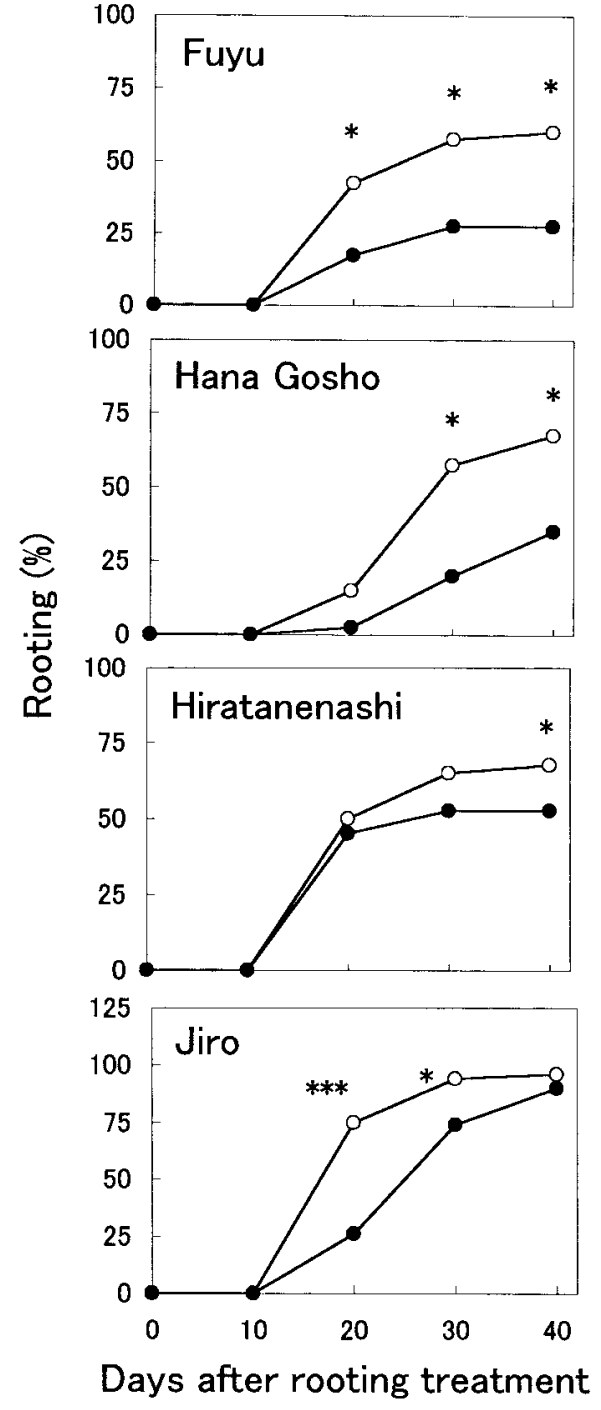

Fig. 2. Rooting percentage of shoots regenerated from roots $(\bigcirc)$ and those that originated from shoot tips (-) of four Japanese persimmon cultivars. Within cultivars and days, asterisks indicate significant difference at $P \leq 0.005$ $(* * *)$ or $0.05(*)$ by ANOVA. Values are means of four replications consisting of 10 shoots each.

leaves while cultured on the rooting medium and grew better after potting. Furthermore, the fact that rooted shoots from 'Hiratanenashi' roots were superior in survival and top dry weight after potting to those that originated from shoot tips might be related to juvenility.

In our previous study (Tetsumura and Yukinaga, 1996), we reported that adventitious shoots arose directly from the root tissue, not from callus, while histological investigations in the present study revealed that their origin was the pericycle tissue, as in Citrus aurantifolia (Christm.) Swing (Bhat et al., 1992). Direct organogenesis is preferable in the micropropagation industry in order to avoid producing somaclonal variants (Islam et al., 1996). Bhat et al. (1992) have inferred that pericycle cells are stable, indicating no apparent aberrations in the chromosomes of plants 
regenerated from roots. Even after passing through a callus phase, plants regenerated from roots seemed to be true-to-type (Jones et al., 1984; Srivastava et al., 1985). Although the sample size was small, the field performance of trees regenerated from roots in the present study also showed no variants. Therefore, this scheme may have commercial application.

Precocity is usually inconsistent with rejuvenation, which is assumed to cause a higher rooting ability of shoots regenerated from roots. After field establishment, however, the trees regenerated from roots began to flower as early as those micropropagated from shoot tips or grafted onto seedlings. Hence, the phase of the shoots regenerated from roots was not completely, but only partially rejuvenated, as reported by Tao et al. (1994).

In conclusion, shoots regenerated from roots appear to be useful for micropropagation of the Japanese persimmon, for both difficultto-root and easy-to-root cultivars. This may facilitate the adoption of micropropagated trees in commercial orchards where initial vigorous growth is desirable (Tetsumura et al., 1999).

\section{Literature Cited}

Banno, K., K. Yoshida, S. Hayashi, and K. Tanabe. 1989. In vitro propagation of Japanese pear cultivars. J. Jpn. Soc. Hort. Sci. 58:37-42.

Bhat, S.R., P. Chitralekha, and K.P.S. Chandel. 1992. Regeneration of plants from long-term root culture of lime, Citrus aurantifolia (Christm.) Swing. Plant Cell Tissue Organ Cult. 29:19-25.

Bonga, J.M. 1982. Vegetative propagation in relation to juvenility, maturity, and rejuvenation, p. 387412. In: J.M. Bonga and D.J. Durzan (eds.). Tissue culture in forestry. Martinus Nijhoff, The Hague, Netherlands.
Del Tredici, P. 1995. Shoot from roots: A horticultural review. Arnoldia 55:11-19.

Druart, P. 1980. Plantlet regeneration from root callus of different Prunus species. Scientia Hort. 12:339-342.

Fukui, H., K. Nishimoto, and M. Nakamura. 1992. Varietal differences in rooting ability of in vitro subcultured Japanese persimmon shoots. J. Jpn. Soc. Hort. Sci. 61:821-825.

Furukawa, H., C. Matsubara, and N. Shigematsu. 1990. Shoot regeneration from the roots of prairie gentian (Eustoma grandiflorum (Griseb.) Schinners). Plant Tissue Cult. Lett. 7:11-13.

Islam, R., M. Hossain, M.A. Reza, A.N.K. Mamun, and O.I. Joarder. 1996. Adventitious shoot regeneration from root tips of intact seedlings of Aegle marmelos. J. Hort. Sci. 71:995-1000

Jones, O.P., J.A. Gayner, and R. Watkins. 1984. Plant regeneration from callus tissue cultures of the cherry rootstock Colt (Prunus avium $\times P$. pseudocerasus) and the apple rootstock M. 25 (Malus pumila). J. Hort. Sci. 59:463-467.

Masuda, T., H. Bessho, S. Komori, and S. Tsuchiya. 1994. Effect of thidiazuron and casamino acid on adventitious shoot formation from roots of apple (Malus prunifolia Borkh. MO-84) plantlets cultured in vitro (in Japanese with English summary). J. Jpn. Soc. Hort. Sci. 63:39-43.

Murashige, T. and F. Skoog. 1962. A revised medium for rapid growth and bioassays with tobacco tissue cultures. Physiol. Plant. 15:473-497.

Murayama, H., R. Tao, T. Tanaka, and A. Sugiura. 1989. In vitro shoot proliferation and rooting of several Japanese persimmon cultivars (in Japanese with English summary). J. Jpn. Soc. Hort. Sci. 58:55-61.

Robinson, J.C. and W.W. Schwabe. 1977. Studies on the regeneration of apple cultivars from root cuttings. I. Propagation aspects. J. Hort. Sci. 52:205-220.

Sriskandarajah, S., M.G. Mullins, and Y. Nair. 1982. Induction of adventitious rooting in vitro in difficult-to-propagate cultivars of apple. Plant Sci. Lett. 24:1-9.

Srivastava, P.S., A. Steinhauer, and H. Glock. 1985.
Plantlet differentiation in leaf and root cultures of birch (Betula pendula Roth.). Plant Sci. 42:209-214.

Tamura, M., R. Tao, and A. Sugiura. 1992. Highly stable regeneration from long-term cultures of Japanese persimmon callus. HortScience $27: 1048$.

Tao, R., J. Ito, and A. Sugiura. 1994. Comparison of growth and rooting characteristics of micropropagated adult plants and juvenile seedlings of persimmon (Diospyros kaki L.). J. Jpn. Soc. Hort. Sci. 63:537-541.

Tao, R. and A. Sugiura. 1992a. Micropropagation of Japanese persimmon (Diospyros kaki L.), p. 424 440. In: Y.P.S. Bajaj (ed.). Biotechnology in agriculture and forestry, Vol. 18: High-tech and micropropagation II. Springer-Verlag, Berlin.

Tao, R. and A. Sugiura. 1992b. Adventitious bud formation from callus cultures of Japanese persimmon. HortScience 27:259-261.

Tetsumura, T. 1997. Effect of types of cytokinin used for in vitro shoot proliferation of Japanese persimmon on the subsequent rooting of shoots. Acta Hort. 436:143-148.

Tetsumura, T., R. Tao, and A. Sugiura. 1991. Effect of cytokinin types on the in vitro propagation of Japanese persimmon (Diospyros kaki Thunb.) (in Japanese with English summary). Plant Tissue Cult. Lett. 8:209-211.

Tetsumura, T., R. Tao, and H. Yukinaga. 1999. Orchard growth, flowering and fruiting of micropropagated Japanese persimmon trees. J. Hort. Sci. Biotechnol. 74:251-253.

Tetsumura, T., R. Tao, and H. Yukinaga. 1993. Factors influencing acclimatization of 'Nishimurawase' Japanese persimmon micropropagules and their field performance (in Japanese with English summary). J. Jpn. Soc. Hort. Sci. 62:533-538.

Tetsumura, T. and H. Yukinaga. 1996. Highfrequency shoot regeneration from roots of Japanese persimmon. HortScience 31:463-464.

Zimmerman, R.H. and I. Fordham. 1985. Simplified method for rooting apple cultivars in vitro. J. Amer. Soc. Hort. Sci. 110:34-38. 